\title{
Life history of Patagonian squid Loligo gahi and growth parameter estimates using least-squares fits to linear and von Bertalanffy models
}

\author{
K. R. Patterson* \\ Falkland Islands Development Corporation, Stanley, Falkland Islands
}

\begin{abstract}
Size and sexual maturity of a large number of Loligo gahi Orbigny 1835 from commercial trawler catches around the Falkland Islands were recorded. Data are explained by proposing that the squid have a 1 yr lifespan and that the population consists of 2 stocks, one spring-spawning and one autumn-spawning. Degree of mixing between the stocks was not assessed. Linear and von Bertalanffy equations are used to model the growth of the spring-spawning stock. Both models fit the data nearly equally well, the linear fit yielding slope $=0.0237$ for males $(0.0199$ for females) $\mathrm{cm}$ dorsal mantle length $\mathrm{d}^{-1}$ growth rate and the von Bertalanffy fit yielding $K=0.00304(0.00308) \mathrm{d}^{-1}, L_{\infty}=19.6(17.8) \mathrm{cm}$, $t_{0}=-101.4(-113.6)$ d from 1 Jan. This growth rate is surprisingly fast given the cold water temperatures around the Falklands, and suggests that food was plentiful for this species.
\end{abstract}

\section{INTRODUCTION}

Squid species are of great ecological importance and represent a huge biomass throughout the oceans of the world (reviews by e. g. Clarke 1985, 1986). Large stocks of squid inhabit the deep seas, where many predators rely entirely on squid for food (Clarke 1987), but shelf squids also support substantial fisheries. The average annual world commercial catch has been approximately 1 to 1.5 million tonnes (Rathgen \& Voss 1987) making squids the sixth most important type of 'fish' in world catches.

The basic biology of nearly all the species including the commercially important ones is still poorly known. Species being caught commercially are frequently inadequately defined taxonomically and for many areas even the number of species contributing to the fishery is unclear. Even basic biological data on many species remain unknown, although these are likely to be critical for the understanding of the effects of fishing pressure on fish stocks.

An increasing proportion of world cephalopod catches is coming from the Patagonian shelf area

\footnotetext{
- Present address: Overseas Development Administration, Ecuador Fisheries Project, LACPD, Eland House, Stag Place, Landon, United Kingdom
}

(Csirke 1987). Here Patagonian squid Loligo gahi Orbigny $1835(=$ L. patagonica Smith 1881) constitute one of the major economic resources of the area, with an annual catch value exceeding US $\$ 50$ million, yet virtually nothing is known of its biology (Anon 1974, Lipinski 1979a, Otero et al. 1983, FAO 1983, Csirke 1987).

Commercial fishery for Loligo gahi takes place around the Falkland Islands in 2 'fishing seasons' within the year. These run from February until May (austral autumn) and from late July until mid-October (austral spring). The pattern of catches is illustrated in Fig. 1, which shows the trend in catch rates by Spanish fishing vessels that fished for $L$. gahi in 1984 . A similar trend was observed in 1985 and 1986.

The fishing grounds lie on the edge of the continental shelf in about 140 to $150 \mathrm{~m}$ depth and to the south, east and northeast of the Falkland Islands (Fig. 2). Samples were taken from across the entire fishing area.

As part of a programme of offshore fishery research the Falkland Islands Government spent some effort in initiating basic biological studies on this species. The main priorities were to describe the major characteristics of the life cycles of the squid, and to assess spawning time, longevity and growth as an aid to stock management. A part of this work on Loligo gahi is described here. 


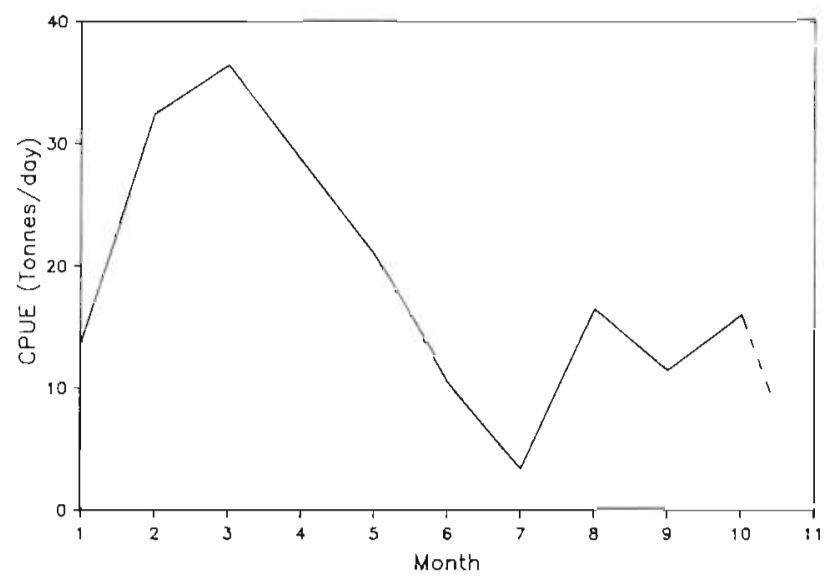

Fig. 1. Loligo gahi. Seasonal variation in the catch rates of Spanish trawlers fishing in 1984. From data in Anon. 1984. No data were available for November and December (see text). CPUE: Catch per unit effort

\section{METHODS}

Samples of squid were collected by shipboard observers placed by the Falkland Islands Government on Japanese and Spanish fishing vessels. The ships were the Japanese fishing vessels 'Taiyo Maru No. 83', 'Banshu Maru No. 6' and 'Banshu Maru No. 7' and the Spanish vessel 'Pescavigo Dos'.

The observers collected random samples of Loligo gahi from trawl hauls made when fishing for $L$. gahi in the above-mentioned areas. Sampling began in October 1985 and ceased in late September 1986, but no sampling was done during November and December 1985. At this time catch rates are very poor and uneconomic. Consequently there was no commercial fishing at this time and no samples could be obtained. For convenience in the analysis the October 1985 samples have been analysed as if they had been taken in October 1986. During January 1986 no observers were at sea, but samples were obtained from vessels transhipping their catches.

About 50 Loligo gahi individuals per trawl sample were measured and their dorsal mantle length recorded to the nearest centimetre below. The state of maturity of each squid was recorded using Lipinski's (1979b) scale, which can be summarised briefly for both males and females: (I) wholly immature; (II) some sexual development; (III) beginning to mature; (IV) prespawning; (V) spawning.

\section{RESULTS}

Results are interpreted in 2 stages. Firstly the life history of the species is deduced from the observed periods of spawning and recruitment. Secondly the life-

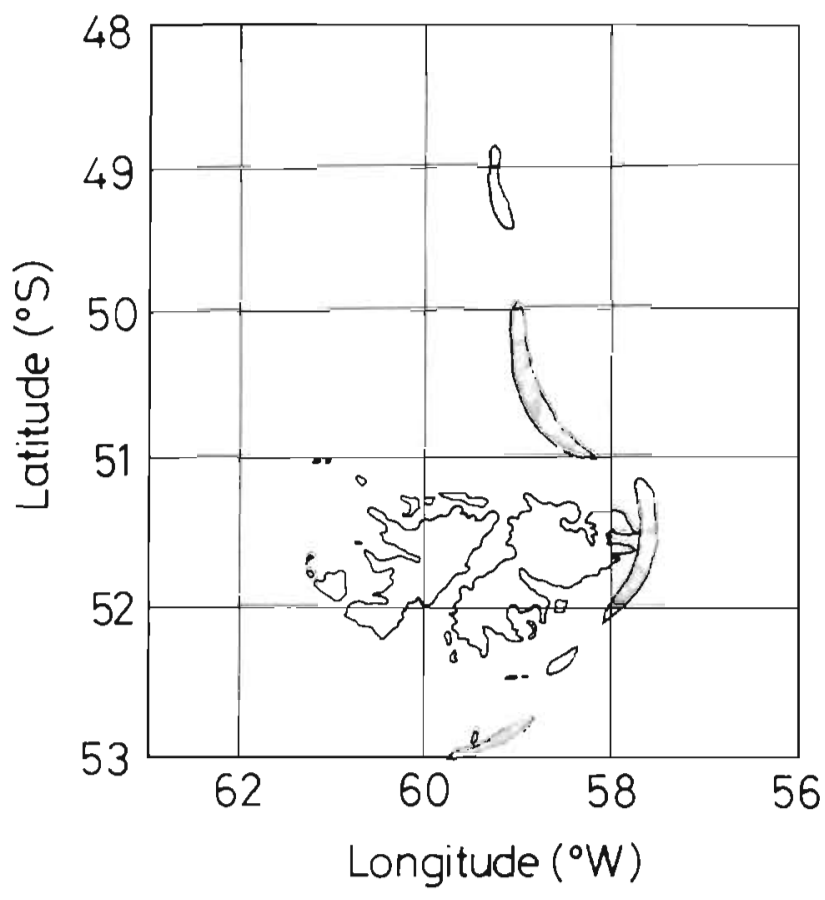

Fig. 2. Loligo gahi. Major fishing areas around the Falkland Islands. All samples were taken from these areas

history information is used to isolate data on a single cohort of squid from the remaining data. A growth model can then be fitted for that isolated cohort. The information available for these deductions is the seasonal pattern of commercial catch rates (Fig. 1) and the distribution of squid by maturity stage and length-class (Figs. 3, 4, 5 and 6, 7, 8 for males and females respectively). The numbers of squid examined in each month are given in Table 1.

\section{Life history}

The most significant processes in the life history of squid are recruitment, spawning, and growth. The approach used here was to look for changes in the sampled population that indicate when recruitment and spawning occur. Thus, recruitment should be manifested by an increase in the proportion of smaller, less sexually mature individuals, and by an increase in the catch rate by numbers (or a faster increase in the catch rate by weight than could be accounted for by growth). Similarly, spawning and senescence must logically be manifested by an increase in the proportion of sexually mature individuals (stages IV and V) and be followed by a decline in commercial catch rate and in the proportion of larger individuals. Once times of recruitment and spawning have been established a life-history model can be proposed, taking into account the recruitment and spawning periods, but making no 
Fig. 3. Loligo gahi males. Lengthfrequency histograms in samples from around the Falklands Islands in January, February, March and April. Histograms are shaded to show the proportions of squid recorded in each gonad maturity stage of Lipinski's 'Universal' scale. See Table 1 for sample sizes

Fig. 4. Loligo gahi males. Lengthfrequency histograms in samples from around the Falkland Islands in May, June, July and August

Fig. 5. Loligo gahi males. Lengthfrequency histograms in samples from around the Falkland Islands in September and October
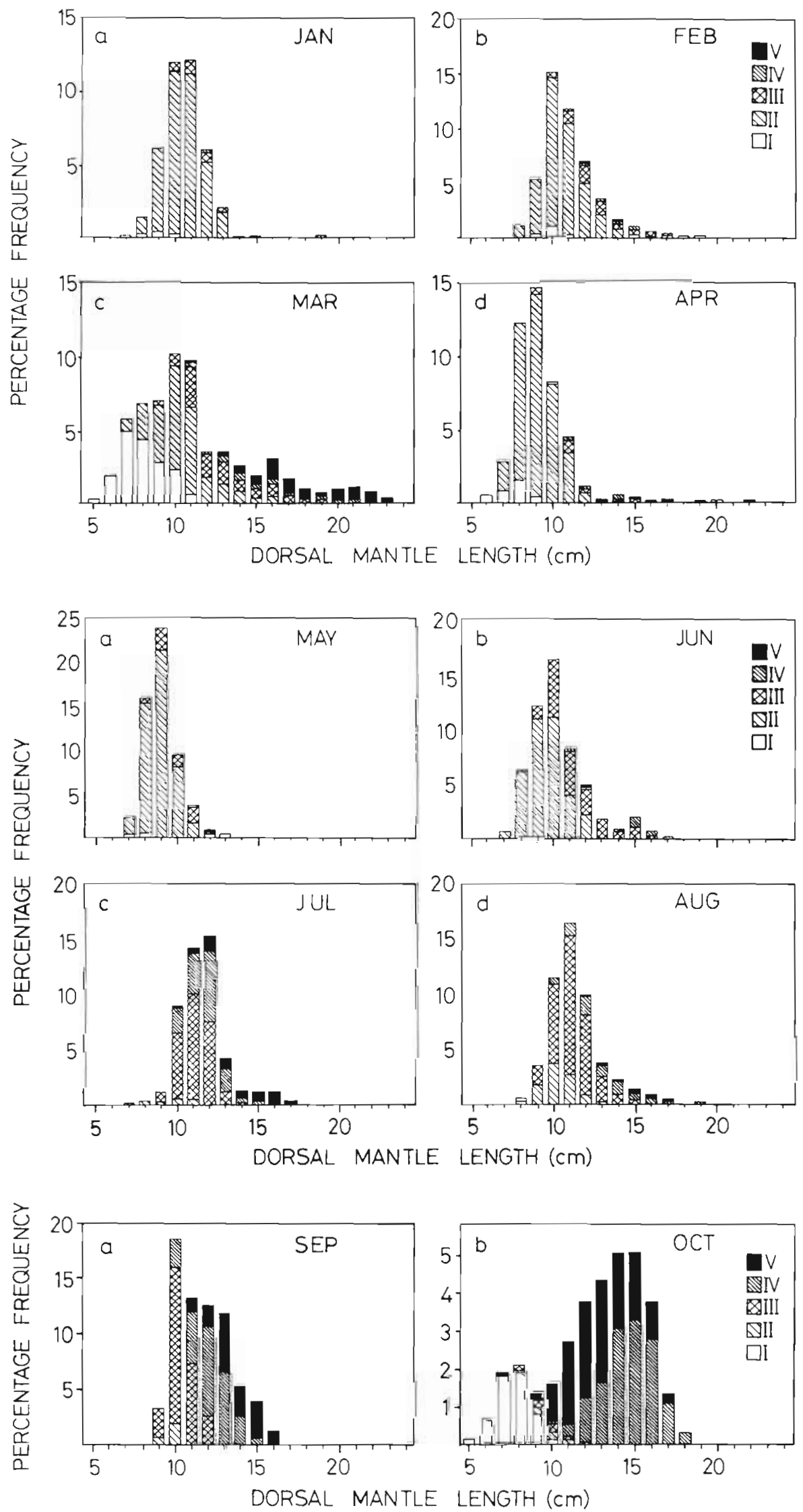


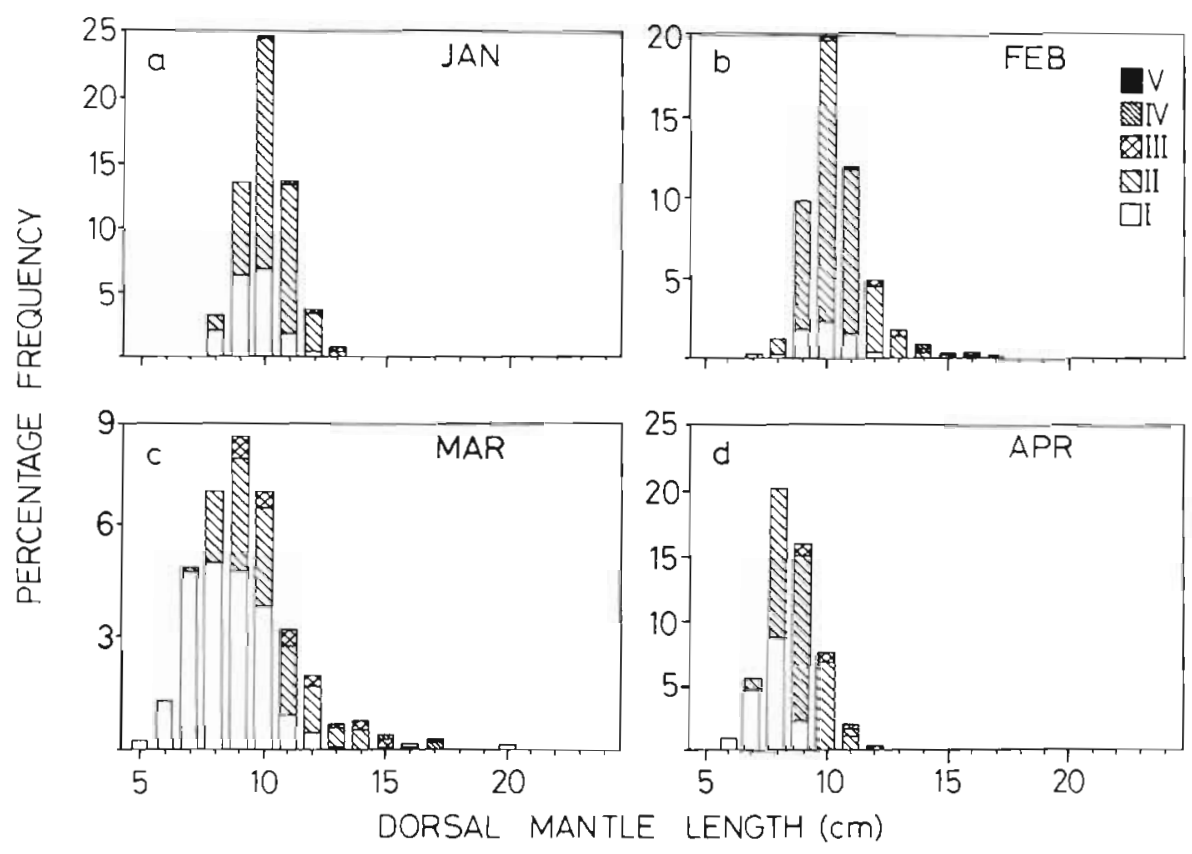

Fig. 6. Loligo gahi females. Length-frequency histograms in samples from around the Falkland Islands in January, February, March and April

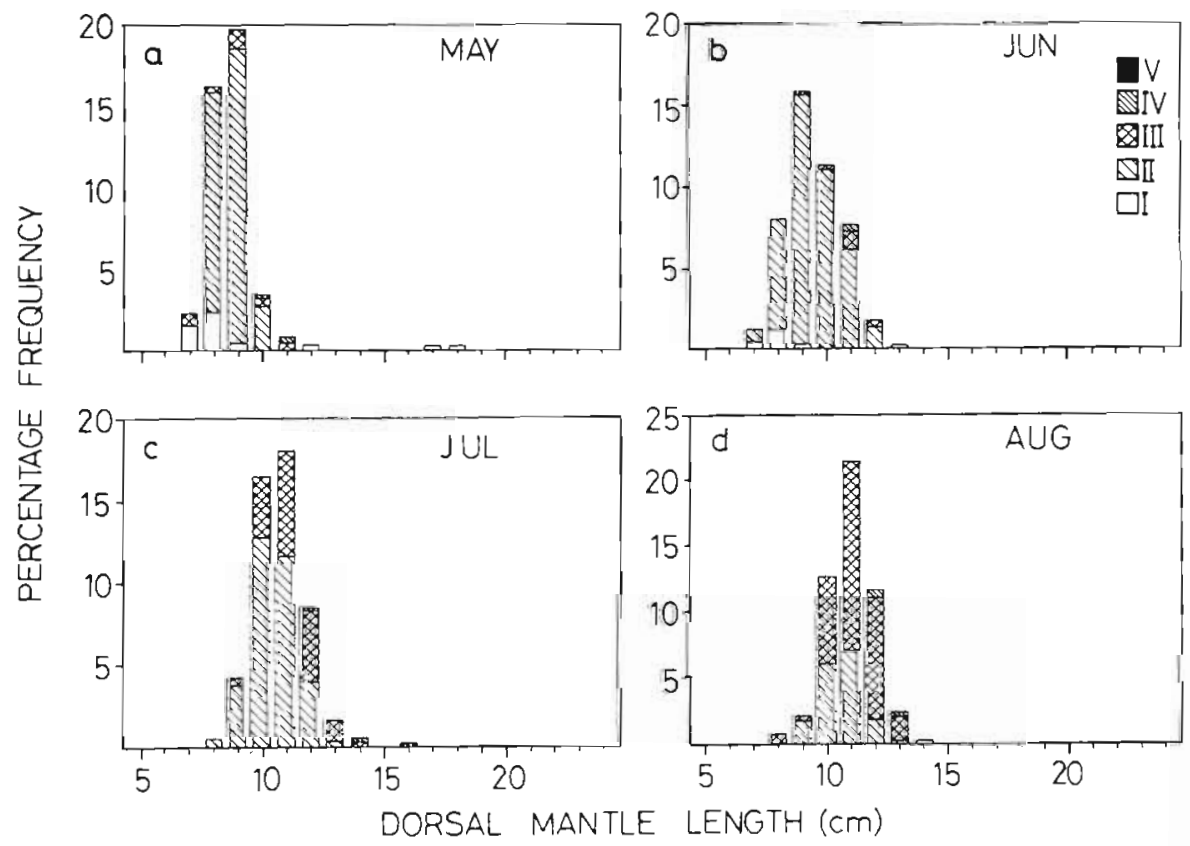

Fig. 7. Laligo gahi females. Length-frequency histograms in samples from around the Falkland Islands in May, June, July and August

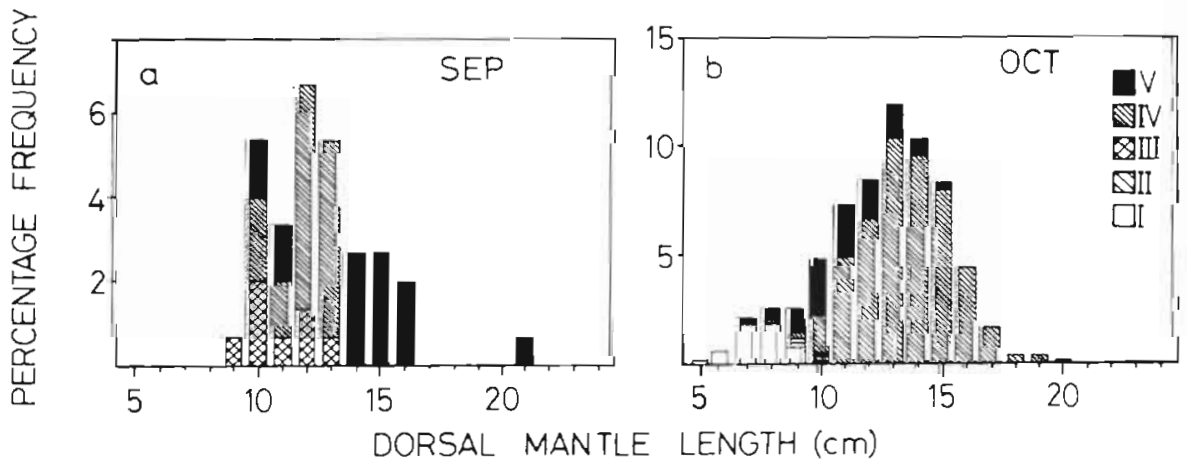

Fig. 8. Loligo gahi females. Length-frequency histograms in samples from around the Falkland Islands in September and October 
unreasonable assumptions about growth patterns. The simplest such model that satisfies the requirements of the data was chosen.

It appears that there are 2 separate periods of recruitment to the fishery. Both are associated with periods of rapidly increasing commercial catch rates (Fig. 1), and both are periods when the proportion of smaller individuals in the population increases. One recruitment occurs between October and January (Figs. 3a, 5b, 6a, $8 \mathrm{~b})$. This population appears in samples in October, when a few small squid of 6 to $9 \mathrm{~cm}$ appear in the samples. In January samples the squid are mostly 9 to

Table 1. Loligo gahi. Sample sizes of males and females taken from commercial trawl catches around the Falkland Islands. Squid were sexed after samples were taken

\begin{tabular}{|crc|}
\hline Month & Males & Females \\
\hline Jan & 250 & 367 \\
Feb & 2470 & 2557 \\
Mar & 825 & 471 \\
Apr & 326 & 376 \\
May & 312 & 238 \\
Jun & 298 & 253 \\
Jul & 988 & 980 \\
Aug & 414 & 423 \\
Sep & 44 & 106 \\
IOct & 2092 & $1079)$ \\
\hline
\end{tabular}

$11 \mathrm{~cm}$. It seems likely that the recruitment may extend from October until January, but due to the unfortunate lack of samples in these months this is rather conjectural. This recruitment is referred to later as November recruitment.

There is evidence for a second, more important, period of recruitment in March and April (Figs. 3c, d, $6 \mathrm{c}, \mathrm{d})$. In this month some smaller squid of 6 to $9 \mathrm{~cm}$ join the squid that had recruited in January. These squid are distinguished by their smaller size but also by their lesser sexual maturation. At this time the commercial catch rate also increases very quickly (Fig, 1). This recruitment is referred to below as an (austral) autumn or March recruitment.

It seems that there are likewise 2 spawning periods. One spawning season, in spring, is very obvious: in September and in October a large part of the squid on the fishing grounds are in spawning or pre-spawning condition (Figs. 5a, b, 8a, b). Many squid clearly spawn at this time. By November the catch rate declined to such an extent that commercial fishing ceased entirely, which was fairly obviously due to post-spawning mortality (Fig. 1).

The evidence for a second spawning in winter is less obvious. The proposal that it occurs has been made to explain the changes in the squid population between
March and April (Figs. 3c, d, 6c, d). In March the population consists of males of a wide range of maturities from immature to spawning, and of females with few pre-spawning individuals. By April however all the spawning male squid and also the larger female squid have left the exploited population, leaving behind only the smaller and less mature individuals. It seems likely that these squid have left the fished areas in order to spawn elsewhere. However the female squid were not very mature in March, so there must be some time delay between leaving the fishing areas and spawning. Presumably the squid feed and grow else-
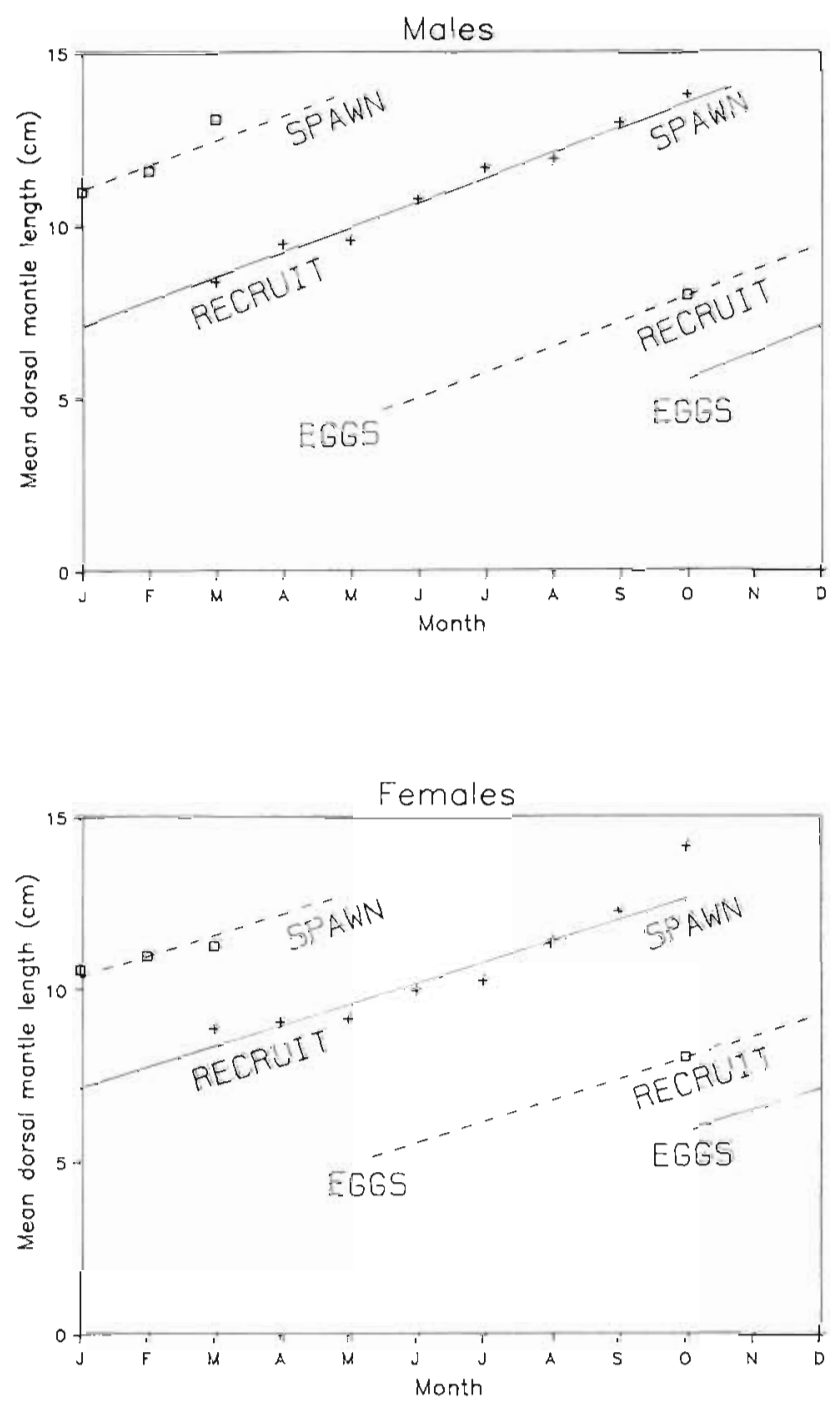

Fig. 9. Loligo gahi. Mean lengths from 2 populations around the Falkland Islands from sample means in successive months. Males (above) and females (below). 1+) Spring-spawners; ( $\square$ autumn-spawners. Continuous lines represent fitted linear growth models for the spring-spawning stock; dashed lines indicate the likely growth of the autumn-spawners. The lines are extended backwards to indicate the respective times of hatching, but this is not intended to represent the early growth pattern 
where as they do not reappear in the exploited population.

Having described 2 periods of recruitment and 2 periods of spawning, it is possible to fit together the observations and to propose a pattern of life histories based on a double annual cycle. A very simple model based on a 1 yr life history and widely variable recruitment and growth does not appear to satisfy the data, because there are 2 distinct periods of spawning and of recruitment showing little evidence of overlapping with each other. The simplest pattern which appears to fit the data is based on a 12 mo life cycle in which 2 populations spawn and recruit 6 mo out of phase with each other. It is of course possible to propose longer life cycles, of 2 yr or $18 \mathrm{mo}$, but such complications to the model are as yet unjustified.

By fitting the observed times of recruitment and spawning to each other, it seems reasonable to suggest that the March recruits spawn in October and that the November recruits spawn around May-June. This suggestion is presented schematically in Fig. 9. It explains the observed pattern of size and maturity of squid and also explains well the seasonal variation in catch rates. The time of peak catch rate (March) coincides with the time when squid from both the 'spring-spawning' and 'autumn-spawning' stocks are available to the fishery. During the spring peak in catch rate (Fig. 1) both proposed populations would be available to the fishery, whilst in the autumn only the autumn-spawning stock is fished. As the autumn peak is only about half the amplitude of the spring peak, one is led to think that the 2 populations may be of similar size.

It is not possible to estimate the degree of mixing or separation of the 2 populations, which could either constitute 2 separate species or stocks, or be 2 spawning periods of a single well-mixed species or stock. However, the fact that the 2 spawnings take place in different areas (one available to the fishery, the other not) suggests that the squid are unlikely to constitute a single stock. This is an area of research where biochemical genetics might be useful in determining the extent of stock separation.

\section{Growth}

Sufficient data were available on the spring-spawning squid to allow simple growth models to be fitted. There were however insufficient data to make the same calculation for the autumn-spawners, as they were unavailable over a larger part of their life cycle. The spring-spawning squid were separated from the others by only considering data from March until October, and by excluding from the analysis immature (Stage I and II) squid caught in October, and also excluding all but the immature squid (Stage I) caught in March.

Two types of model were fitted separately to male and to female squid. A simple linear model was fitted using standard linear regression procedures, and a von Bertalanffy model was fitted using a non-linear regression analysis (Allen 1966). In each case the independent variable (time) was expressed as the number of days from $1 \mathrm{Jan}$; and the dependent variable (dorsal mantle length) was expressed as recorded length + $0.5 \mathrm{~cm}$. Measurements of 4494 male and 3576 female Loligo gahi were used. Results of fitting the models are listed in Table 2. There is little to choose on a purely statistical basis between the linear and von Bertalanffy models: they have closely similar residual sums of squares and explain the data about equally well. All 4 regressions are highly significant $(p<0.0005)$. The linear model explains the growth of males marginally better than the von Bertalanfy model; however the converse is true of the females and the differences are not significant. The linear model is useful in yielding the immediately comprehensible result that male and

Table 2. Parameters obtained by fitting models to Loligo gahi time ( $t$ ) and length ( $)$ data

\begin{tabular}{|c|c|c|c|}
\hline Parameter & Males & Females & Units \\
\hline \multicolumn{4}{|l|}{ Linear model: $(l)=a+b \cdot t$} \\
\hline $\mathrm{b}$ & 0.02372 & 0.0198642 & $\mathrm{~cm} \mathrm{~d}^{-1}$ \\
\hline a & 6.831 & 6.930 & $\mathrm{~cm}$ \\
\hline Residual sum of squares & 15374.03 & 15934.15 & \\
\hline F & 3353.3 & 1148.6 & \\
\hline$r^{2}$ & $43 \%$ & $24 \%$ & \\
\hline \multicolumn{4}{|c|}{ von Bertalanify model: $(l)=L_{x}-L_{x}\left(\mathrm{e}^{-K\left(t-t_{\infty}\right)}\right)$} \\
\hline$K$ & 0.003038333 & 0.003078126 & $d^{-1}$ \\
\hline$L_{\infty}$ & 19.587 & 17.771 & $\mathrm{~cm}$ \\
\hline$t_{0}$ & -101.39 & -113.58 & Days after 1 Jan \\
\hline Residual sum of squares & 15401.689 & 15878.38 & \\
\hline$F$ & 3337.97 & 1164.8 & \\
\hline$r^{2}$ & $43 \%$ & $25 \%$ & \\
\hline
\end{tabular}


female squid grew at some 0.0237 and $0.0198 \mathrm{~cm} \mathrm{~d}^{-1}$ respectively over much of the period of study.

On a biological basis however the von Bertalanffy model does seem to return values that are more likely to have some more general biological significance. Thus the values of $L_{x}$ suggest that male and female squid reach maximum sizes of around 19.6 and $17.8 \mathrm{~cm}$ respectively, values that accord well with observation. The obtained values of $\mathrm{K}, 0.0030 \mathrm{~d}^{-1}$ for males and 0.0031 for females, are useful for comparing results with those from other studies.

The von Bertalanffy model yields estimates of $t_{0}$ the time of theoretical zero length, of about 10 to $23 \mathrm{Sep}$ 1985 (females and males respectively), which also accords well with the suggestion above that these squid would have been hatched in September and October.

\section{DISCUSSION}

In this section likely sources of error and their importance are discussed and the results compared with the findings of earlier workers. The principal problem in this study has been the difficulty of access to random samples from trawl hauls, due to the many limitations imposed by working on commercial fishing vessels the only available source of information. These vessels could not deviate from their commercial practices to improve scientific data collection. Because of this, squid could not be sampled at all desirable times, and there is some doubt as to the comparability of trawl samples by different ships. In general these circumstances have tended to limit the statistical validity of fitting growth models, and these can best be regarded as general indications of the values that Loligo gahi growth rate parameters can take. Nevertheless the restricted access to samples is not likely to have caused major errors in the proposed life history.

\section{Life history}

The use of different ships at different times of year was unavoidable, and casts some doubt on the comparability of results obtained by different ships in different seasons. Gear on the various ships was generally similar, but some minor differences were inevitable. This means that a comparison of length-frequencies is not totally reliable, but there seems no reason why the relation between maturity and size cannot be compared between different months: it seems unlikely that ships might differentially select squid of different maturity stages but the same size. Conceivably a difference in behaviour caused by a different maturity stage could result in a higher vulnerability to one type of trawl than another, but this seems unlikely to be an important effect in the present case because the trawl types were so similar, and mesh selection appears to have had little effect (see below).

Some missing samples hindered interpretation of the data. No information was available for November and December 1985, and sampling could not be continued into October 1986. The problem of the missing data has been overcome in 2 ways. First, by interpolating between October 1985 and February 1986; this seems a straightforward procedure and no problems appear to arise from it. Second, by assuming that there is little difference in the squid populations between years so that the October 1985 samples can be substituted for the lacking October 1986 samples. This substitution is probably justified for determination of the life history as it would take an extremely large difference between the 2 October populations to affect the life history model arrived at here, and such a large difference appears very improbable.

The argument for the proposed double annual cycle model rests in part on the changes in the squid population in March and April, a time when the squid are heavily fished. It could be argued that this change is due to fishing mortality and not to a pre-spawning emigration. However this is unlikely because of the nature of the fishery. All the fishing vessels use finemeshed (ca 1 to $1.5 \mathrm{~cm}$ bar mesh) nets to fish for Loligo gahi on account of the substantial market value of even the smallest individuals. Such nets should remove virtually all the population equally and not select the largest individuals. This does appear to be the case (see Table 3 and below). Further, any suggestion that the loss of larger squid could be due to differential fishing mortality on larger squid would fail to explain the observed maturation of larger squid in March.

Although little previous work has been directed at the biology and life history of Loligo gahi, it is of interest to compare results obtained here with those of workers on loliginid squid in other parts of the world. For example, Holme (1974) described the life cycle and growth of Loligo forbesi in the Plymouth (UK) area. He found this squid to have a 1 yr life history with spawning principally during December and January. However small numbers of mature males and females were recorded throughout spring and early summer. Holme suggested that these are individuals which fail to spawn in winter and therefore spawn in the next year. Although these squid could conceivably be of a separate spring-spawning stock, this seems unlikely as there is no evidence of 2 times of recruitment of smaller squid.

In contrast, Summers (1971) proposes a much more complex schema for the life cycle of Loligo pealei off 
Table 3. Loligo gahi. Summary of length data used to fit growth models. Model fittings were made using actual sampling dates and not using monthly averages

\begin{tabular}{|c|c|c|c|c|c|c|c|c|}
\hline \multirow{2}{*}{$\begin{array}{l}\text { Length } \\
\text { (cm) }\end{array}$} & \multicolumn{8}{|c|}{ Month } \\
\hline & Mar & Apr & May & Jun & Jul & Aug & Sep & (Oct) \\
\hline \multicolumn{9}{|l|}{ Males } \\
\hline 20 & & & & & & & & 6 \\
\hline 19 & & & & & & & & 15 \\
\hline 18 & & & & & & & & 15 \\
\hline 17 & & & & 1 & 8 & 2 & 1 & 40 \\
\hline 16 & & & & 4 & 13 & 10 & 3 & 129 \\
\hline 15 & & & & 11 & 19 & 10 & 4 & 407 \\
\hline 14 & & & & 5 & 36 & 11 & 4 & 324 \\
\hline 13 & & 7 & 3 & 10 & 67 & 37 & 8 & 373 \\
\hline 12 & & 7 & 5 & 27 & 191 & 123 & 10 & 262 \\
\hline 11 & 6 & 31 & 19 & 43 & 308 & 116 & 5 & 222 \\
\hline 10 & 26 & 56 & 51 & 87 & 210 & 114 & 8 & 129 \\
\hline 9 & 34 & 101 & 126 & 64 & 75 & 8 & 1 & 31 \\
\hline 8 & 53 & 85 & 85 & 32 & 10 & 4 & & 15 \\
\hline 7 & 63 & 18 & 11 & 4 & 1 & & & \\
\hline 6 & 25 & 3 & & & & & & \\
\hline 5 & 6 & & & & & & & \\
\hline \multicolumn{9}{|c|}{ Females } \\
\hline 20 & & & & & & & & \\
\hline 19 & & & & & & & & \\
\hline 18 & & & & & & & & 13 \\
\hline 17 & & & & & & & & 41 \\
\hline 16 & & & & & & & 2 & 117 \\
\hline 15 & & & & & & & 6 & 158 \\
\hline 14 & & & & & & & 8 & 158 \\
\hline 13 & & & 3 & 1 & 10 & 17 & 24 & 139 \\
\hline 12 & 5 & 3 & 3 & 11 & 37 & 96 & 26 & 120 \\
\hline 11 & 12 & 14 & 5 & 44 & 166 & 176 & 26 & 79 \\
\hline 10 & 47 & 52 & 23 & 61 & 356 & 102 & 28 & 32 \\
\hline 9 & 63 & 112 & 134 & 85 & 317 & 15 & 5 & 9 \\
\hline 8 & 67 & 143 & 112 & 44 & 84 & 4 & & \\
\hline 7 & 65 & 40 & 16 & 7 & 10 & & & \\
\hline 6 & 14 & 7 & & & & & & \\
\hline 5 & 1 & & & & & & & \\
\hline
\end{tabular}

Woods Hole (Massachusetts, USA). He suggested that although this squid is basically an annual species, some individuals survive for $2 \mathrm{yr}$. He also suggested that there may be 2 spawning seasons, a principal one in July and a less obvious one in November This pattern could possibly be a similar one to that proposed here for L. gahi, although Summers does not go so far as to suggest 2 breeding cycles.

Worms (1983) reports that Loligo vulgaris in the Mediterranean have 2 peak spawning periods, in March and in July. However he estimated that the life span of this species is normally 2 or 3 yr. He did not suggest that the 2 spawnings represented separate stocks, but rather represented early and late spawning of one stock. Worms observations show that the pattern of dual spawning observed in L. gahi around the Falklands is not unique in this genus - evidence that the double annual cycle life history proposed here is not a theoretical extravagance.

\section{Growth}

The assessment of squid growth presents particular difficulties, in contrast to fish, which can be aged relatively easily using otoliths or scales. Some workers have found it possible to age squid by counting daily rings on statoliths (Kristensen 1980, Rosenberg et al. 1980), but it was not practicable to use such a technique in this case due to limitations of manpower, time and relatively poor laboratory equipment in the Falkland Islands.

Summers (1968, 1971) and Hixon et al. (1981) estimated the growth of Loligo pealei by following modes in length classes throughout a period of time. Pauly (1984) criticised these methods for their insufficient objectivity, and recommended the use of more rigorous statistical procedures for finding modes in length-distributions and fitting growth models. Although it was initially intended to use methods similar to those suggested by Pauly, it was found that cohorts could most conveniently be separated by considering squid in different gonad maturity stages separately. The 'Universal' maturity stage of Lipinski (1979b) was used for this purpose. This method was thought preferable to relying on statistical discrimination of modes in lengthfrequencies. Growth models were then fitted to the data after so separating the cohorts.

Three sources of bias that may have affected the growth data are mesh-selection by trawls, the transposition of the October samples, and the use of different fishing vessels to gather samples. A summary of the data used in the model fittings is shown in Table 3 , which is included to make the point that there was little evidence of mesh-selection by trawls affecting representation of the smaller size-classes. In this case it is also unlikely that different mesh-selection between different trawlers can have had an important effect. Table 3 shows that the October 1985 data seem to conform to the general trend observed throughout most of 1986 . Even if growth rates were substantially different between years, the main effect this would have on the model output would be to yield a growth rate estimate that is some value between that in each of the 2 yr. Such an estimate is still valuable. In summary, although the statistical procedure was not entirely correct in that sampling vessels were not standardised and the October data are transposed, it seems that the model fits given here are little affected by these errors and probably give a good general indication of the growth rate of Loligo gahi.

Some other field studies on the growth of loliginid squid have been completed and can be compared with present results. Workers on Loligo pealei off New England (USA) estimated $L_{*}$ and $K$ at $38.3 \mathrm{~cm}$ and 0.0016 respectively (Ikeda \& Nagasaki 1975). For the same 
species in the Gulf of Mexico values of $23.0 \mathrm{~cm}$ and 0.0026 were obtained by Pauly (1984) using data from Hixon et al. (1981). These values compare with the presently values of $19.6 \mathrm{~cm}$ and 0.0030 (males) and 17.8 $\mathrm{cm}$ and 0.0031 (females), suggesting that L. gahi may be faster-growing but reaching a lower asymptotic size than $L$. pealei in the wild. It is somewhat surprising to find that the colder-water species L. gahi is the smaller, faster-growing one. A reason for this can tentatively be advanced.

The slower growth of Loligo pealei in the wild does not appear to be a physiological limitation, but rather a nutritional one. Hanlon et al. (1983) have shown that $L$. pealei can grow as fast as $0.144 \mathrm{~cm} \mathrm{~d}^{-1}$ if kept in captivity and fed to satiation at a high temperature. The very much faster growth under laboratory conditions suggests that $L$, pealei in the wild are largely limited in growth by food availability. This limitation appears to be less serious in the case of L. gahi, which despite a lower environmental temperature shows a higher growth rate. This observation is consistent with the general observation that food is scarcer in warmer waters than in temperate areas. Casual observation of stomach contents of $L$. gahi suggests that their principal food consists of the lobster-krill or squat lobster Munida bamffica, which is abundant around the Falkland Island (C. Garrod pers. comm.).

\section{CONCLUSIONS}

The double annual cycle model for the life history of Loligo gahi explains the data and is robust to the likely sources of error introduced by suboptimal sampling. There exists a precedent for this type of life history in a loliginid squid. The sampling procedures are not rigorously correct for regression model fitting, but an inspection of the likely sources of bias suggests that the estimates of growth rates are sound general estimates of the growth rates of this species.

Acknowledgements. I thank the shipboard observers, Messrs T. Flood, J. Martin and J. Barton, for collecting the specimens at sea, and Miss M. Basson and Miss D. Kohn for assisting with data typing. I also thank Captain J. Parada for inviting me to work on his ship. Drs P. Rodhouse, A. Rosenberg and D. Pauly made helpful comments on the manuscript.

\section{LITERATURE CITED}

Allen, K. R. (1966). A method of fitting growth curves of the von Bertalanffy type to observed data. J. Fish. Res. Bd Can. 23 (2): 163-179

Anonymous (1974). Informe del grupo de trabajo conjunto CAIRM/CARPAS sobre la evaluacion cientifica del estado de los stocks en el Atlantico sudoccidental. F.A.O., Comision Asesora de Pesca para el Atlantico Sudoccidental (CARPAS/6/74/4)

Anonymous (1984). Report of the Spanish southwest Atlantic catches in 1984. ANAMER, Vigo (mimeo)

Clarke, M. R. (1985). Cephalopods in the diets of cetaceans and seals. Rapp. Comm. Int. Mer Medit. 29: 211-219

Clarke, M. R. (1986). Cephalopods in the diets of odontocetes. In: Bryden, M. M., Harrison, R. (eds.) Research on dolphins. Oxford Univ. Press, Oxford, p. 281-322

Clarke, M. R. (1987). Biomass of cephalopods-estimation from predation. In: Boyle, P. R. (ed.) Cephalopod life cycles. II. Comparative reviews. Academic Press, London, p. $221-238$

Csirke, J. (1987). The Patagonian fishery resources and the offshore fisheries in the South-West Atlantic. F.A.O. Fish. Tech. Pap. 286: 1-75

FAO (1983). Informe del Grupo Ad hoc de Trabajo sobre los recursos pesqueros de la plataforma continental Patagonica, Roma, 7-11 febrero 1983. Una reunion preparatoria para la conferencia mundial de la FAO sobre ordenacion y desarrollo/Report of the Ad hoc working group on fishery resources of the Patagonian shelf, Rome, 7-11 Feb 1983. A preparatory meeting for the FAO world conference on fisheries management and development. F.A.O. Inf. Pesca/F.A.O. Fish. Rep. 297

Hanlon, R. T., Hixon, R. F., Hulet, W. H. (1983). Survival, growth and behavior of the loliginid squids Loligo plei, Loligo pealei, and Lolliguncula brevis (Mollusca: Cephalopoda) in closed sea water systems. Biol. Bull. mar. biol. Lab., Woods Hole 165: 637-685

Hixon, R. F., Hanlon, R. T., Hulet, W H. (1981). Growth and maximal size of the long-finned squid Loligo pealei in the northwestern Gulf of Mexico. J. Shellfish Res. 1 (2): 181-185

Holme, N. A. (1974). The biology of Loligo forbesi Steenstrup (Mollusca: Cephalopoda) in the Plymouth area. J. mar. biol. Ass. U. K. 54: 481-503

Kristensen, T. K. (1980). Periodical growth rings in cephalopod statoliths. Dana 1: 39-51

Lipinski, M. (1979a). Glowonogi poludnio-zachodniego Atlantyku/Studium eksploatacyjne/ (Cephalopods of the South-West Atlantic [A field study.]). Marine Fishing Institute, Gdynia

Lipinski, M. (1979b). Universal maturity scale for the commercially important squids. The results of maturity classification of the Illex illecebrosus population for the years 1973-77. International Commission for the Northwest Atlantic Fisheries (ICNAF), Res. Doc. 79/2/38, Serial No. 5364

Otero, H. O., Bezzi, S. I., Verazay, G. A., Perez Comas, J. A., Perrotta, R. G., Simonazzi, M. A., Renzi, M. A. (1983). Distribucion, areas de concentracion, biomasa $Y$ rendimiento potencial de diferentes especies comerciales del mar Argentino, Contrib. Inst. Nac. Invest. Des. Pesq. 433: $39-87$

Pauly, D. (1984). The population dynamics of short-lived species, with emphasis on squids. North Atlantic Fisheries Organisation (NAFO) Sci. Coun. Studies 9: 143-154

Rosenberg, A. A., Wiborg, K. F., Bech, I. M. (1980). Growth of Todarodes sagittatus Lamarck (Cephalopoda, Ommastrephidae) from the northeast Atlantic based on counts of statolith growth rings. Sarsia 66: 53-57

Rathgen, W. F., Voss, G. L. (1987). The cephalopod fisheries: a review. In: Boyle, P. R. (ed.) Cephalopod life cycles. II. Comparative reviews. Academic Press, London, p. 253-275 
Summers, W. C. (1968). The growth and size distribution of current year class Loligo pealei. Biol. Bull. mar. biol. Lab., Woods Hole 135: 366-377

Summers, W C. (1971). Age and growth of Loligo pealei, a population study of the common Atlantic coast squid. Biol.
Bull. mar. biol. Lab., Woods Hole 141 189-201

Worms, J. (1983). Schema migratoire d'une population de Loligo vulgaris Lam. (Cephalopoda, Teuthoidea) du Golfe de Lion (France). Rapp. Comm. int. Mer Medit. 28 (5): $277-279$

This article was submitted to the editor; it was accepted for printing on March 11, 1988 